\title{
A Proposed Mechanism for the Thickening Behavior of SiC- Polyethylene Glycol Abrasive Slurry during Silicon Ingot Slicing into Wafers for Photovoltaic Applications
}

\author{
Ronald Allan S. de los Reyes
}

\begin{abstract}
The present study presents a mechanism to account for the transformation of silicon carbide - polyethylene glycol abrasive slurries into thick slurries. Based on comparative observations and the results of other workers, it is proposed that the thickening behavior is the result of siloxane bonds forming bridges that connect the kerf or silicon particles which eventually increases the density of the slurry. It is further suggested that the source for this reaction would be the polyethylene glycol itself due to its possible degradation into smaller compounds after repeated use in the cutting operation.
\end{abstract} words)

Keywords-SiC, PEG, thick, slurry, silicon, photovoltaic (key

\section{Introduction}

In the conversion of $\mathrm{SiO}_{2}$ (quartz) into silicon photovoltaic cells, part of the value chain of processes is what is called wafering. In this process, a continuous strand of stainless steel wire about 120 microns in diameter is wound around two parallel guide rollers forming a bed of about 2,500 - 3,000 loops from the line of wire. A silicon ingot of around $800 \mathrm{~mm}$ in length is slowly pressed down on this bed of wire transforming it into 2,500 to 3,000 slices or wafers of about 150 microns to 200 microns in thickness. The machine used for this process is called a wiresaw machine. The slicing of the ingot into thousands of wafers is done simultaneously over a period of about 6 to 8 hours depending on the size of the ingot.

The wiresawing process has two types - the fixed abrasive machining wherein the wire is coated with diamond grits and does the actual cutting and the free abrasive machining wherein the wire only acts as a carrier of the cutting slurry medium. This slurry consists of a suspension of micron size silicon carbide abrasive particles ( $\mathrm{SiC}$ ) in a liquid coolant. The liquid coolant commonly used is polyethylene glycol 200300 (PEG). The stability of the suspension of this slurry directly affects the efficiency and quality of the ingot slicing and will be the main focus of this study particularly the behavior of thick slurry formation.

Ronald Allan S. de los Reyes, Ph.D.

Malayan Colleges Laguna

Philippines

\section{Methods and Materials}

Four types of slurries were used with different levels of kerf (Si particles) loading. The kerf loading corresponds to the number of times the batch of slurry was used in the cutting process.

The slurry samples were designated as follows:

$$
\begin{aligned}
& \text { Slurry A - not used (fresh mix) } \\
& \text { Slurry B - used } 1 \text { time } \\
& \text { Slurry C - used } 2 \text { times } \\
& \text { Slurry D - used } 3 \text { times }
\end{aligned}
$$

Comparative kerf loading amount : $\mathrm{D}>\mathrm{C}>\mathrm{B}>\mathrm{A}$

It is conjectured that the $\mathrm{OH}^{-}$ion concentration is a critical factor in the formation of thick slurry. To explore this hypothesis, an equal amount of $\mathrm{KOH}$ basic solution was added at room temperature to the slurry samples and the reaction was monitored over time to determine if the thickening will occur. As an added confirmatory study, a suggested method of neutralizing the reaction was performed with the use of sodium acetate. This will be explained further in the next section.

\section{Results and Discussion}

\section{A. Addition of KOH Solution}

The following figures will show the effect of adding the $\mathrm{KOH}$ solution to the slurry samples monitored over several time periods.

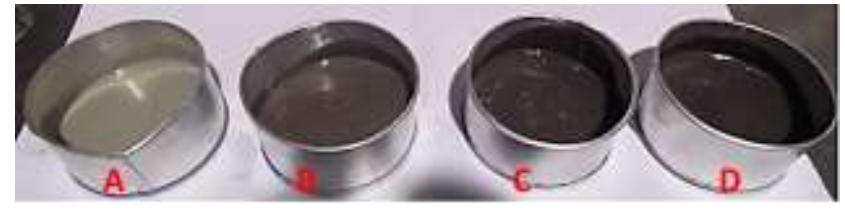

Figure 1. Slurries with $\mathrm{KOH}$ after 2:53 min.

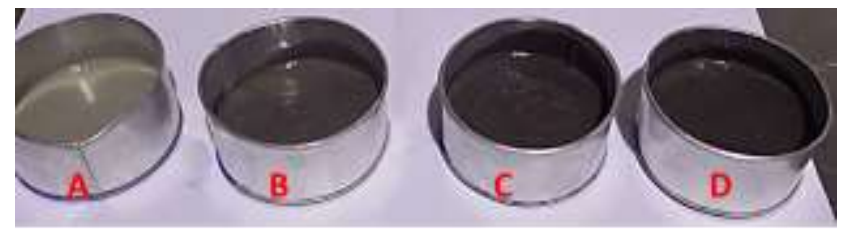

Figure 2. Slurries with KOH after 3:40 min 


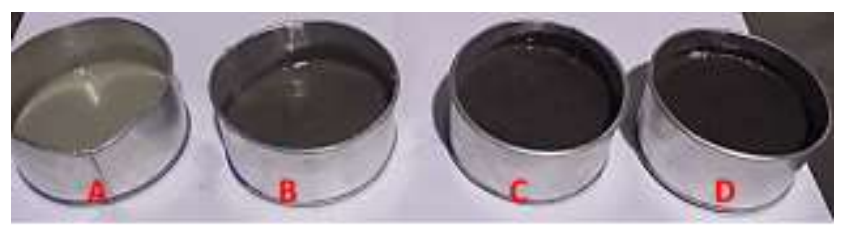

Figure 3. Slurries with KOH after 4:39 min.

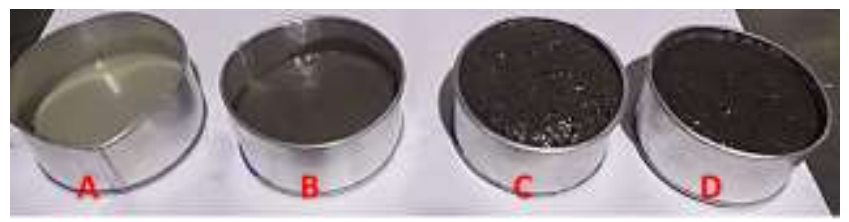

Figure 4. Slurries with $\mathrm{KOH}$ after 5:10 min.

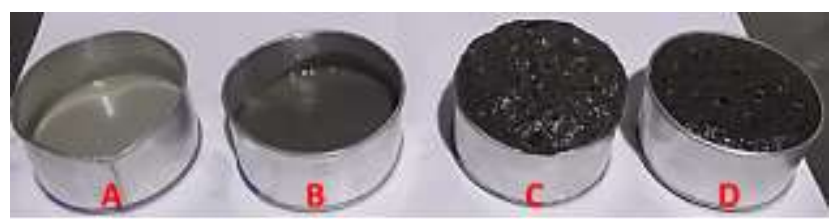

Figure 5. Slurries with $\mathrm{KOH}$ after 5:55 min.

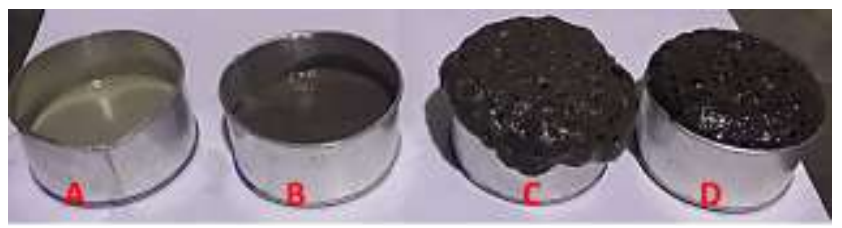

Figure 6. Slurries with $\mathrm{KOH}$ after 6:17 min.

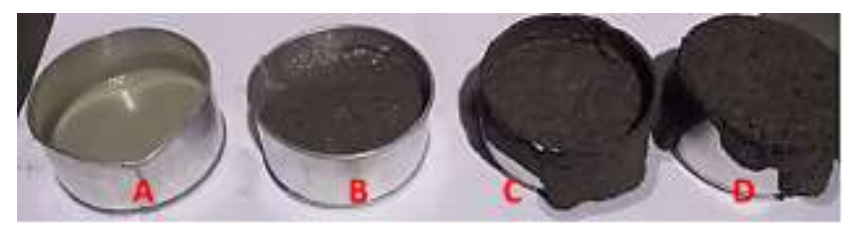

Figure 7. Slurries with KOH after 13:25 min.

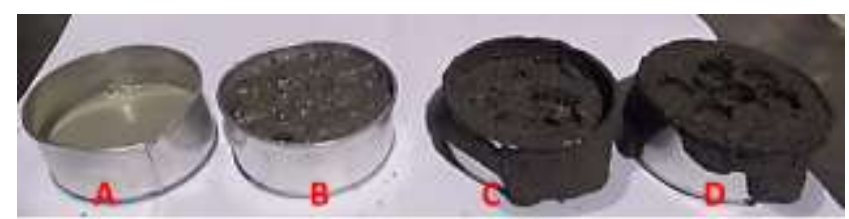

Figure 8. Slurries with KOH after 14:40 min.
From the above Figures 1 to 8 it is readily observed that there is a marked difference in the reaction of the slurries with $\mathrm{KOH}$ from each other. The slurry with the highest kerf loading, D, reacted immediately and transformed into thick slurry. On the other hand, the slurry with no kerf loading, A, did not exhibit any change in its consistency. The degree of reaction follows the order of the slurries in terms of their kerf loading, that is $\mathrm{D}>\mathrm{C}>\mathrm{B}>\mathrm{A}$.

\section{B. Addition of $\mathrm{KOH}+$ Sodium Acetate}

Figure 9 shows the behavior of the slurries with the addition of $\mathrm{KOH}$ and sodium acetate. It is clearly seen that with the addition of the sodium acetate the development of the thick slurry was arrested as compared to the reactions as shown above.

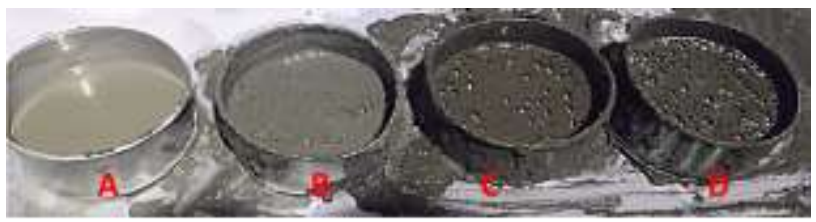

Figure 9. Slurries with $\mathrm{KOH}+$ Sodium Acetate.

To confirm this result, a solution of sodium acetate only was added to the slurries shown below in Figure 10.

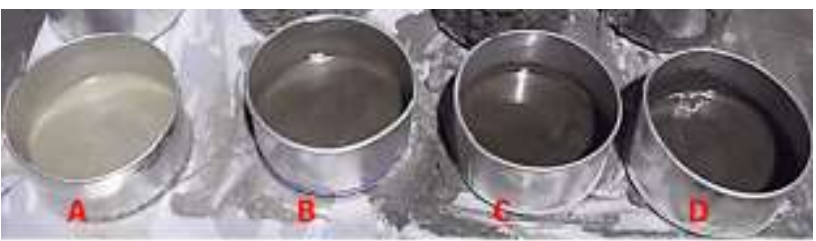

Figure 10. Slurries with Sodium Acetate.

It seen that there is no appreciable reaction of the sodium acetate with the slurries. Thus it can be said that the addition of sodium acetate prevented the reaction of the slurries with the $\mathrm{KOH}$ from going to completion.

\section{Proposed Mechanism}

\section{A. Siloxane Bridging}

Basu et al. [1] explained that the complex molecule, silicon hydroxide, $\mathrm{Si}(\mathrm{OH})_{4}$, can be produced by the reaction of silicon with $\mathrm{OH}^{-}$ions. This reaction proceeds according to the following equations:

$$
\begin{aligned}
& \mathrm{NaOH} \leftrightarrow \mathrm{Na}^{+}+\mathrm{OH}^{-} \\
& \mathrm{Si}+4 \mathrm{OH}^{-} \leftrightarrow \mathrm{Si}(\mathrm{OH})_{4}
\end{aligned}
$$

Furthermore, Griesmar et al. [2] have elucidated that the silanol, $\mathrm{Si}-\mathrm{OH}$, group of the silicon hydroxide molecule can bond with another silanol group according to the following equation:

$$
\mathrm{SiOH}+\mathrm{SiOH} \leftrightarrow \mathrm{Si}-\mathrm{O}-\mathrm{Si} \text { (siloxane bonds) }+\mathrm{H}_{2} \mathrm{O}
$$


This reaction produces siloxane bonds and water as a byproduct (condensation reaction).

It is now proposed that these siloxane bonds act as bridges that form networks of Si particles. After a certain critical mass is reached, these networks eventually coalesce and transform the suspension into thick slurry.

\section{B. Source of $\mathrm{OH}^{-}$ion}

This gives rise to the question as to where the excess $\mathrm{OH}^{-}$ can come from during the cutting process. The most likely source of chemical species would be the polyethylene glycol that has a general chemical formula of $\mathrm{H}-\left(\mathrm{O}-\mathrm{CH}_{2}-\mathrm{CH}_{2}\right)_{\mathrm{n}}-\mathrm{OH}$. Research studies have analyzed the fragmentation of PEG under thermal energy. An example of this is the work of Kitahara et al. [3] who have identified several products of decomposition from a sample of PEG heated from $20^{\circ} \mathrm{C}$ to $600^{\circ} \mathrm{C}$ using an ion mass spectrometer. Moreover, Bhagavat and Kao [4] with the use of finite element analysis determined that the temperature inside the cutting groove or channel reaches to about $45^{\circ} \mathrm{C}$ to $50^{\circ} \mathrm{C}$. Also the degradation of PEG by sludge microbes has also been extensively studied as in the work of Huang et al. [5]. It is here suggested that the $\mathrm{OH}^{-}$ion came from the PEG itself. Under the harsh conditions of the cutting process inside the cutting groove which may include microbial activity, partial degradation of the PEG occurs contributing to the rise of the $\mathrm{OH}^{-}$concentration.

\section{Action of Sodium Acetate}

Figure 11 shows a comparison of the behavior of silicon particles in $\mathrm{KOH}$ solution and in $\mathrm{KOH}+$ Sodium Acetate solution.

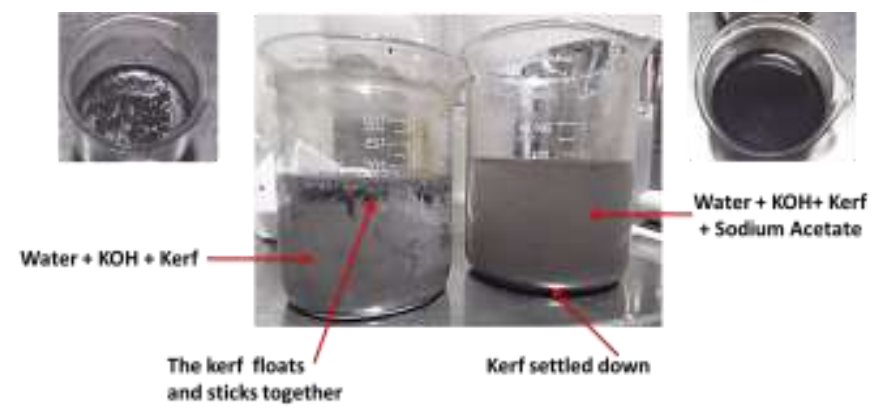

Figure 11. Kerf behavior in $\mathrm{KOH}$ solution and in $\mathrm{KOH}+$ Sodium Acetate solution.

It is seen that the kerf in the solution with sodium acetate settled out of the suspension and deposited on the bottom of the beaker. In contrast, the kerf in the $\mathrm{KOH}$ solution remained in suspension and formed aggregates of silicon particles. It is supposed that the acetate ion bonded with the very reactive silicon particles which caused their sedimentation out of suspension.

\section{Summary}

From the evidences does far gathered, it can be surmised that thick slurry formation in SiC-PEG abrasive slurries occurs through the following process :

1. Due to the extreme conditions inside the cutting groove partial degradation of the PEG occurs after repeated use of the slurry. This increases the concentration of the $\mathrm{OH}^{-}$ion concentration in the slurry.

2. This fragmentation process is further augmented by the action of microbes in the slurry breaking up the PEG molecule into smaller compounds releasing more $\mathrm{OH}^{-}$ions.

3. Repeated use of the slurry increases the kerf or silicon particles cut from the silicon ingot.

4. The surface of the silicon particles are very reactive due to the presence of the dangling bonds. These readily react with the negatively charged $\mathrm{OH}^{-}$ions.

5. Si-OH particles bond with each other forming networks of particles eventually changing the suspension into thick slurry.

The results also show that the addition of sodium acetate neutralizes the above reaction. The $\mathrm{Na}^{+}$ion reacts with the $\mathrm{OH}^{-}$ion while the acetate ion may have passivated the surface of the silicon particles. The passivation neutralizes the electronic charges on the surface of the silicon particles enabling these to come together and sediment out of the suspension.

\section{v. Recommendations}

The SiC-PEG abrasive slurry is a dynamic, complex, "living" system. The purpose of this study is to identify the various factors that may contribute to thick slurry formation for further investigations. Suggested areas can be the following :

1. Characterization of the conditions inside the cutting groove.

2. Chemical analysis of the PEG after every cut.

3. Microbial action in the PEG during the cut and in storage.

4. Zeta potential analysis of the Si particle surface in PEG.

\section{References}

[1] P.K. Basu, H. Dhasmana, D. Varandani, B.R. Mehta, D.K. Thakur, A cost-effective alkaline multicrystalline silicon surface polishing solution with improved smoothness, Solar Energy Materials \& Solar Cells 93 (2009) 1743-1748.

[2] P. Griesmar, A. Ponton, S. Serfaty, B. Senouci, M. Gindre, G. Gouedard, S. Warlus, Kinetic study of silicon alkoxides gelation by acoustic and rheology investigations, Journal of Non-Crystalline Solids 319 (2003) 57-64.

[3] Yuki Kitahara, Seiji Takahashi, Toshihiro Fujii, Thermal analysis of polyethylene glycol: Evolved gas analysis, with ion attachment mass spectrometry, Chemosphere 8 (2012) 663-669. 
[4] Sumeet Bhagavat, Imin Kao, A finite element analysis of temperature variation in silicon wafers during wiresaw slicing, International Journal of Machine Tools \& Manufacture 48 (2008) 95-106.

[5] Yi-Li Huang, Qing-Biao Li, Xu Deng, Ying-Hua Lu, Xin-Kai Liao, Ming-Yuan Hong, Yan Wang, Aerobic and anaerobic biodegradation of polyethylene glycols using sludge microbes, Process Biochemistry 40 (2005) 207-211.

About Author (s):

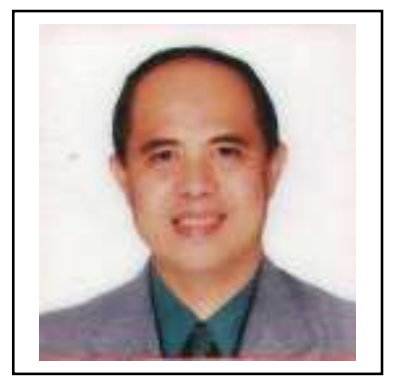

Dr. Ronald Allan S. de los Reyes, is an Associate Professor at Malayan Colleges Laguna. His most recent research projects were on silicon photovoltaic wafer manufacturing done in the industry.

"It is here suggested that the $\mathrm{OH}^{-}$ ion came from the PEG itself. Under the harsh conditions of the cutting process inside the cutting groove which may include microbial activity, partial degradation of the PEG occurs contributing to the rise of the $\mathrm{OH}^{-}$ 